\title{
Analysis of Changes in Seismicity Pattern for Probabilistic Seismic Hazard Analysis (PSHA) and Mitigation: Mapping Probability Difference before the Large Earthquake and Its Implementation in PSHA \& Mitigation around Northern Sumatra
}

Wahyu Triyoso ( $\square$ wtriyoso@gmail.com )

Bandung Institute Of Technology https://orcid.org/0000-0002-8561-839X

Tedi Yudistira

Institut Teknologi Bandung

David P. Sahara

Institut Teknologi Bandung

Research Letter

Keywords: Probability of Occurrence, Probability Difference, Seismic Quiescence Index, Large Earthquakes, PSHA map, PGA, PE

Posted Date: June 29th, 2020

DOI: https://doi.org/10.21203/rs.3.rs-36859/v1

License: (c) (1) This work is licensed under a Creative Commons Attribution 4.0 International License.

Read Full License 
Analysis of Changes in Seismicity Pattern for Probabilistic Seismic Hazard Analysis (PSHA) and

Mitigation: Mapping Probability Difference before the Large Earthquake and Its

Implementation in PSHA \& Mitigation around Northern Sumatra

Wahyu Triyoso ${ }^{1^{*}}$, MSc, PhD, Tedi Yudistira ${ }^{{ }^{*}}$, DR, David P. Sahara ${ }^{1^{*}}$, DR. Rer. Nat

* These authors contributed equally to this work

${ }^{1}$ Global Geophysics Group, Faculty of Mining and Petroleum Engineering, Bandung Institute of

Technology, Jl. Ganesha10, Bandung 40132, West Java

Word Count: 4434 words (main body) with 3 figures

Article submitted to Geoscience Letters, AOGS Journal

Version: 1

Corresponding author: Wahyu Triyoso, Ph. D. Global Geophysics Group, Faculty of Mining and

Petroleum Engineering, Bandung Institute of Technology, Jl. Ganesha10, Bandung 40132, West Java, Indonesia.

Tel.: +62 22 2534137, Fax: +62 22 2534137, E-mail: wtriyoso@gmail.com

\section{Abstract}

The probability difference before the occurrence of a large earthquake is mapped in the northern part of Sumatra, taking the range of Region Time Length (RTL) before a major earthquake (December 26, 
2004) around 15 years. By normalizing the absolute value of probability difference between two periods of RTL and before RTL, the Seismic Quiescence Index (SQI) is then defined. Probability difference analysis is done by dividing observations of shallow earthquake periods into two periods based on the similarity gradient of the annual earthquake production, namely 1963-1990 and 1991-November 2004. The results showed that areas with relatively high SQI were consistent with the presence of major earthquake events after November 2004 to 2016 that are sorted by a radius of 300 $\mathrm{km}$ with the center point being the epicenter position of the December 2004 earthquake. The implementation of the SQI was then used for probabilistic seismic hazards study and analysis based on an integrated model that is derived based on the estimated of seismicity rate of around the subduction zone and active fault of Sumatra Fault Zone (SFZ) sources. The map of Probabilistic Seismic Hazard Analysis (PSHA) is then constructed based on Peak Ground Acceleration (PGA) estimated for a $10 \%$ Probability Exceedance (PE) level in 50 years. The results of this study may be very useful for earthquake mitigation and modeling efforts for PSHA going forward.

Keywords: Probability of Occurrence, Probability Difference, Seismic Quiescence Index, Large Earthquakes, PSHA map, PGA, PE 


\section{INTRODUCTION}

Based on the results of previous studies it can be concluded that the presence of earthquake precursors is shown by changing the pattern of seismicity (gradient seismicity rate) in space-time in certain seismotectonic areas that correlate strongly with the phenomenon of the existence of zones and periods of seismic quiescence before major earthquake events (Wyss \& Habermann, 1988). Identification and interpretation of patterns of change in the presence of zones and periods of gradient seismicity rate before a major earthquake in seismic hazard studies and mitigation efforts require careful analysis and modeling based on selected of the appropriate reference model to express the natural sensitivity of evolution or changes in seismicity patterns evolution, both in space and time. To go forward analysis or forecasting efforts that can be linked to the possibility of future seismic hazard analysis or future mitigation, the pattern that may express is a clustering model that can be observed or extracted from earthquake data (Michael 1997). One method that is often applied to extract clustering models is by applying seismicity smoothing using a Gaussian function to earthquake catalog data (Frankel, 1995). Some previous studies have implemented the above algorithm for example, (Frankel 1995, Petersen et al. 2008, Triyoso \& Shimazaki, 2012, Triyoso et al. 2020a, Triyoso et al. 2020b).

Sukrungsri \& Pailoplee (2016) evaluated the model changes in seismic patterns before the 2004 Aceh Earthquake and the 2012 Indian Ocean earthquake by applying the RTL algorithm. The results obtained support the existence of a quiescence zone and period phenomenon where it is concluded that the presence of a quiescence zone and period is highly correlated with the seismotectonic process which could be associated with stress perturbation phenomenon before a major earthquake event. The results of a more detailed analysis based on the earthquake catalog dataset indicate the presence of 
temporal and spatial variations which can be concluded to reveal or express characteristics that are consistent with changes in seismicity patterns.

Referring to the definition of Seismic Quiescence by Wyss and Habermann (1988), in this study the identification of quiescence zones in the RTL period is quantified using probabilities so that it can be quantified and mapped two difference, probability models. They are before the quiescence period and during the quiescence period. Furthermore, the probability difference between the two models can be calculated. By normalizing the probability difference, the scale or index quantification of the quiescence period is obtained as a function of probability difference. This index is proposed as the Seismic Quiescence Index or SQI. The implementation of SQI in the preparation of the PSHA map to be used to characterize or estimate the level of seismic hazard in the future can be done by building a seismicity rate model resulting from the merging of subduction zones and active fault data, then weighted by the SQI for the same study area. Furthermore, a Probabilistic Seismic Hazard Analysis (PSHA) map of Peak Ground Acceleration (PGA) was constructed for a $10 \%$ Probability of Exceedance (PE) level in 50 years. Estimates of the long-term geology of large earthquake slip rates are based on Billham et al. (2005). Active fault data is based on Natawidjaja (2017). For earthquake catalog data the PUSGEN 2017 catalog (PUSGEN 2017) is used, by applying a correlation distance in the implementation of the seismicity smoothing algorithm of $75 \mathrm{~km}$ (Frankel, 1995). The RTL period selected before major earthquake events is based on the gradient analysis of cumulative shallow earthquake production after the declustering process of the 2017 PUSGEN catalog data. The relatively long RTL period is indicated by the presence of a quiescence period before the major earthquake event of 26 December 2004 (Katsumata, 2015) wherein this study it was taken about 15 years, namely the period 1991 to November 2004. While the period 1963 to 1990 could be categorized as a period with 
background seismicity with the gradient rate is greater than the quiescence period in RTL. The data used for the SQI implementation in the PSHA analysis and mitigation is based on the integration data and method of the previous study (Triyoso et al., 2020a, 2020b), to obtain a more stable of the long-term seismicity rate model.

\section{DATA AND METHODS}

The seismic data to develop the probability models used in this study are based on the PUSGEN 2017

(PUSGEN, 2017) in which the earthquake data with the magnitude of $\mathrm{M}_{\mathrm{W}} \geq 5.0$ and a maximum depth of $50 \mathrm{~km}$ around a $400 \mathrm{~km}$ radius with the center radius is the epicenter of the December 26, 2004 earthquake is selected. The spatial b-value is estimated based on the results of a constant radius of 150 $\mathrm{km}$ of shallow earthquake catalog data $\left(\mathrm{M}_{\mathrm{c}} \sim 4.7, \mathrm{H} \leq 50 \mathrm{~km}\right.$ from 1963 to 2016). The selected earthquake catalog is then carried out by the declustering process to get an earthquake event that is mutually free or independent. The declustering process is carried out using ZMAP software (Wiemer, 2001). The data for the PSHA is based on the merging between two models. They are models around the subduction zone and active fault sources. Data around subduction zone is based on the results of Triyoso et al. (2020a), where the A-value model of Gutenberg-Richter (1944), estimated by the weighting the normalized seismic moment rate with mean seismicity smoothing and a correlation distance of $25 \mathrm{~km}, 50 \mathrm{~km}$, and $150 \mathrm{~km}$ of $\mathrm{M}_{\mathrm{w}} \geq 5.0, \mathrm{H} \leq 50-\mathrm{km}$ of the years 1963 to 2016 . The active fault data is based on the results of the new revised (simplified) active fault map of the Sumatran Fault Zone (SFZ) according to the PuSGeN Team for Updating Indonesia Seismic Hazard Map with new slip rates from geological and geodetical (GPS) recent studies (Natawidjaja, 2017). A-values for active fault data modeled by integrating shallow earthquake data from PUSGEN $2017\left(\mathrm{M}_{\mathrm{w}} \geq 5.0, \mathrm{H} \leq 50 \mathrm{~km}\right.$ of the 
years 1963 to 2016) around the active fault zone and synthetic catalog data constructed from active fault distribution data. The algorithm for constructing synthetic catalog models is based on Triyoso and Shimazaki (2012), which in this study modeled earthquake epicenter positions are distributed uniformly along with the active fault position for each interval of about 10-km distance. Subsequent synthetic epicenter distribution data was smoothed with a distance correlation of $25 \mathrm{~km}$. For shallow earthquake data around the active fault zone, the application of the seismicity smoothing algorithm is based on the study of Frankel (1995) by applying smoothing with a correlation distance of $75 \mathrm{~km}$. Integration between the two models is done by weighting the A-value model from the earthquake catalog with normalized smoothed seismicity obtained from active fault data.

\subsection{Seismicity Smoothing}

In this study, the application of the seismicity smoothing algorithm with the Gaussian kernel is based on the results of previous studies (Frankel 1995, Petersen et al. 2008, Triyoso \& Shimazaki, 2012, Triyoso et al. 2020a, Triyoso et al. 2020b) which were applied to seismic hazard analysis. In brief, the application and process sequence of this algorithm can be described as follows; the initial stage is to conduct a gridding study area then in each grid the number of earthquakes is calculated that is greater or equal to the reference magnitude $\left(\mathrm{M}_{\mathrm{ref}}\right)$. This quantity is the number of earthquake events whose maximum likelihood is the value of $10^{\mathrm{a}}$ or the value of $\mathrm{A}$ in the Gutenberg-Richter equation (Gutenberg and Richter, 1944) for earthquake events greater or equal to $M_{r e f}$ (Bender, 1983). Data on each grid with this value is then smoothed spatially by using seismicity smoothing algorithm with the kernel in the form of a Gaussian function with a correlation distance $c$ (Frankel, 1995). Referring to Triyoso et al. (2020a), for each cell or grid $i$, the value of the smoothed seismicity can be obtained from: 


$$
\tilde{\mathbf{n}}_{\mathrm{i}}=\frac{\sum_{\mathrm{j}} \mathrm{n}_{\mathrm{i}} \mathrm{e}^{-\Delta^{2}{ }_{\mathrm{ij}} / \mathrm{c}^{2}}}{\sum_{\mathrm{j}} \mathrm{e}^{-\Delta^{2}{ }_{\mathrm{ij}} / \mathrm{c}^{2}}}
$$

where $\tilde{n} i$ is the normalized value to preserve the total number of earthquake events, $\Delta i j$ is the distance between the grid $i$ and grid $j, \mathrm{c}$ is the correlation distance. In equation (1), the summation or addition process is carried out on the grid $j$ with a distance of $3 c$ from the grid $i$.

\subsection{Seismicity Rate Function}

Following Triyoso et al. (2020a), the theoretical rate function for a given grid or $v_{i}\left(\geq M_{r e f}\right)$ is estimated by the equation,

$$
\mathrm{v}_{\mathrm{i}}\left(\geq \mathrm{M}_{\text {ref }}\right) \approx \frac{\mathrm{N}_{\mathrm{i}}}{\mathrm{T}}
$$

where $N_{i}$ is the number of earthquakes with magnitude $\geq \mathrm{M}_{\text {ref }}$ on the grid $i$ and $T$ is the observation period. $v_{i}$ is a quantity of $10^{\mathrm{a}}$ for earthquake events with magnitude greater than or equal to $M_{r e f}$. So the application of the Gaussian function for seismicity smoothing is to set the value of $10^{\mathrm{a}}$ based on equation (2). By substituting equation (2) with equation (1), we can write the following equation,

$$
\mathrm{v}_{\mathrm{i}}(\geq \mathrm{m}) \approx \frac{\tilde{\mathrm{n}}_{\mathrm{i}}\left(\geq \mathrm{M}_{\mathrm{ref}}\right)}{\mathrm{T} \cdot \mathrm{b} \ln (10)} 10^{-\mathrm{bm}}\left(1-10^{\mathrm{b}\left(\mathrm{m}^{-} \mathrm{M} \max \right)}\right)
$$

where $\tilde{n}_{i}\left(\geqslant \mathrm{M}_{\mathrm{ref}}\right)$ is the quantity of the smoothed value for grid $i$ which is expressed as the number of earthquakes with magnitude greater or equal to the reference magnitude during the period of $T$ years, with a certain $b$-value. In this study, the $b$-value is estimated spatially based on the result of a constant 
radius of $150 \mathrm{~km}$ of shallow earthquake catalog $\left(\mathrm{M}_{\mathrm{c}} \sim 4.7, \mathrm{H} \leq 50 \mathrm{~km}\right.$ of the years 1963 to 2016) and $\mathbf{M}_{\max } \sim 9.2$ (Triyoso et al. 2020a).

\subsection{Probability of occurrence}

The probability of an earthquake with a magnitude greater than or equal to the reference magnitude $m$ on the $i$-th grid during the time interval T below the Poisson distribution is given by,

$$
p(\geq \boldsymbol{m})=1-\exp \left(-v_{i}\right)
$$

where $p(\geq \mathrm{m})$ is the probability of occurrence of the quantity of seismicity smoothed on the grid $i$ for the number of earthquakes with magnitudes greater or equal to the reference magnitude $(\mathrm{m})$.

\subsection{Probability Difference: Seismic Quiescence Index}

Decreased earthquake activity can occur in part from or on all mainshock volumes or from mainshock to the next mainshock. The downward trend in seismic activity trend or decrease in gradient rate of seismicity can continue until a major earthquake or mainshock occurs or a downward trend can occur in a relatively short period before the occurrence of a major earthquake which further increases the trend in earthquake activity. Therefore, the duration of the search for zones and periods of quiescence is very dependent on tectonic activity and structure, loading rate, and stress perturbation which are important parameters related to the likelihood of earthquake precursors that will occur. The application of these terminology zones and quiescence periods as precursors of large earthquakes has been used in many seismic studies in various parts of the world and also the Andaman-Northern 
Sumatra (eg, Katsumata and Kasahara, 1999, Cao and Gao, 2002, Tsapanos et al. 2014; 2016, Sukrungsri \& Pailoplee, 2016).

Referring to the definition of Seismic Quiescence by Wyss and Habermann (1988), in this study the identification of quiescence zones in the RTL period is quantified with probabilities so that it can be quantified and mapped two probability models before the RTL in the quiescence period and during RTL period. Furthermore, by normalizing the probability difference, the scale or index quantification of the zone and quiescence period as a function of the spatial probability difference for a particular RTL period will be 0 to 1 . This index is defined as the Seismic Quiescence Index or SQI. For better understanding the pattern of seismicity changes in the perspective of seismic hazard studies from the perspective of probability in the future, the SQI is included as one of the components or parameters in the preparation of the PSHA map. The implementation of SQI into the PSHA analysis and mitigation is based on models with a longer observation period, they are model of Triyoso et al. (2020a and 2020b) intending to get a more stable and representative mean long-term seismicity rate model.

\subsection{Probability of Exceedance (PE)}

Following the previous study (Triyoso and Shimazaki, 2012, Triyoso et al., 2020a, 2020b), the PE of the annual peak ground motion of the horizontal component denotes by $u$ at the position of a particular observation point due to the source event on the $k$-th grid which is assumed to have a Poisson distribution is given by:

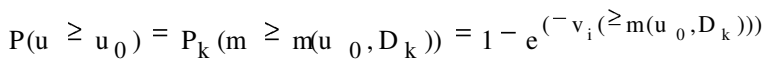


where $\mathrm{P}_{\mathrm{k}}\left(\mathrm{m} \geq \mathrm{m}\left(\mathrm{u}_{o}, \mathrm{D}_{\mathrm{k}}\right)\right)$ is an annual PE level of an earthquake occurrence in the $k$-th grid with $m\left(u_{o}\right.$, $D_{k}$ ) is the magnitude of $m$ which is in the position of the $k$-th source grid which will produce a peak ground motion with the quantity is equal to or greater than $u_{o}$ at observation point position with $D_{k}$ is the distance of observation point to the source position. The function $m\left(u_{o}, D_{k}\right)$ is the GMPE model selected and applies to a particular source model. The probability distribution of peak ground motion (PGA or PGV) at the observation point position is determined by calculating the total probability of all influence sources of a given radius and is estimated by the following equation.

$$
\left.\mathrm{P}\left(\mathrm{u} \geq \mathrm{u}_{0}\right)={ }_{1}-\prod_{(1}-\mathrm{P}_{\mathrm{k}}\left(\mathrm{u} \geq \mathrm{u}_{0}\right)\right)
$$

With the substitution of the selected GMPE equation, equation (6) can be written the following equation,

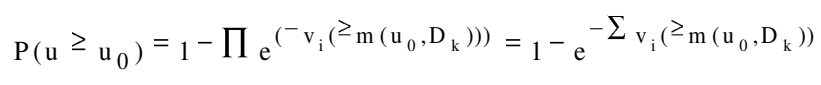

The above equation gives an annual estimate of the PE level for a given peak ground motion value. For the given $\mathrm{T}$ year period, equation (7) can be written as follows,

$$
\mathrm{P}\left(\mathrm{u} \geq \mathrm{u}_{0}\right)={ }_{1}-\left(1-\mathrm{P}\left(\mathrm{u} \geq \mathrm{u}_{0}\right)\right){ }^{\mathrm{T}}={ }_{1}-\mathrm{e}^{\left(-\mathrm{T} \sum_{\mathrm{v}_{\mathrm{i}}}\left(\geq_{\mathrm{m}}\left(\mathrm{u}_{0}, \mathrm{D}_{\mathrm{k}}\right)\right)\right)}
$$

The annual PE level of a given value of the peak of the ground motion is calculated by applying equation (7) for each grid. For a certain duration of time $T$, the PE level of a specified peak ground 
motion is calculated using equation (8).

\subsection{Ground Motion Prediction Equation (GMPE)}

In this study, an evaluation of potential hazards, where the source is a megathrust or a subduction zone, refer to the results of Triyoso et al. (2020a) and select GMPE based on Atkinson et al. (2006) and Zhao et al. (1997). For the SFZ sources, the PGA is estimated by referring to the results of Natawidjaja and Triyoso (2007) in which the GMPE of Fukushima and Tanaka of 1990 is used and then it is updated with the GMPE of Fukushima and Tanaka of 1992.

\section{Result and Discussion}

Figure $1 \mathrm{~A}$ is the result of the annual seismicity rate model of the study area with a radius of $400 \mathrm{~km}$ with the center being the epicenter of the earthquake of December 26, 2004, with Mw $\geqslant 5.0$, generated by data before the RTL period. It is the period of the year of 1963 to 1990. Figure 1B is the annual seismicity rate model in the RTL period. It is the period of the year of 1991 to November 2004. Figure 1C shows the result of the spatial b-value estimated based on the constant radius of $150 \mathrm{~km}$ of shallow earthquake catalog $(\mathrm{Mc} \sim 4.7, \mathrm{H} \leqslant 50 \mathrm{~km}$ of the years 1963 to 2016). Based on Figure 1 (A and B), the difference in a gradient from the rate of earthquake production can be seen by the presence of zones and periods of quiescence.

Figure 2A shows the normalized probability difference in this study is defined as the Seismic Quiescence Index (SQI) which is based on the results of Figure 1 (A and B). Figure 2B shows the integration between two models, they are model around subduction zone and active fault sources in which data around subduction zone is based on the results of Triyoso et al. (2020a) and the active fault data is based on the integration between the two models of weighting the A-value of the shallow 
earthquake catalog with normalized smoothed seismicity obtained from active fault data. Figure $2 \mathrm{C}$ is the annual seismicity rate model obtained based on the combination of two models, they are model around subduction zone and active fault sources weighted with the SQI model. The results show that the SQI is consistent with the places where the sorted of major earthquakes occurred from December 2004 to 2016 with the radius around $300 \mathrm{~km}$. The result of this study may be very beneficial for the sake of earthquake mitigation and modeling efforts for PSHA going forward. Based on the results of Figure 2 (A and C), it can be identified the existence of a quiescence zone that may have the potential to be filled with large or relatively large earthquake events that are located around the western zone of the island of Nias, northern Sumatra Island where some have already filled by inland earthquake events around Pidie in 2016 and the mainland zone around Lake Toba.

Furthermore, the PSHA map was constructed based on the SHF estimation which is a curve between probabilities exceeded vs. PGA. The total probability at the each of observation points for the source is estimated for the magnitude range of 6.0 to 9.0. The calculation is based on Triyoso et al. (2020a) where the parameters that influence are the magnitude change by 0.5 and the distance of the observation point to the source of the earthquake with a radius of $100 \mathrm{~km}$. The source depth value is taken as half of the seismogenic thickness which is around $10 \mathrm{~km}$ and the starting locking depth at 3 km depth. By using equation 8 and GMPE (Natawidjaja and Triyoso, 2007 and Triyoso et al., 2020a), the PGA for the 10\% PE level can be calculated for 50 years. Figure 3, is the mean PGA map between of three differences GMPE of $10 \%$ PE level of 50 years, where the SQI is included.

\section{CONCLUSIONS}

In this study, identification of the quiescence zone in the RTL period is quantified based on the probability difference between the two probability models before the quiescence period and during the RTL period. By normalizing the probability difference, the scale or index quantification of the zone or 
area of the quiescence as a function of the spatial probability difference that is defined as the SQI. The results are consistent with the places of the sorted of major earthquakes that occurred from December 2004 to 2016 with the radius around $300 \mathrm{~km}$. The implementation of SQI into the PSHA analysis and mitigation is done by weighting the model with the SQI that is based on a longer observation period to get a more stable and representative mean long-term seismicity rate model. The existence of a quiescence zone that may have the potential to be filled with large or relatively large earthquake events is located around the western zone of the island of Nias, northern Sumatra Island where some have already filled by inland earthquake events around Pidie in 2016 and the mainland zone around Lake Toba. The result of this study might be very beneficial for the sake of earthquake mitigation and modeling efforts for PSHA going forward.

Availability of data and materials

Earthquake Catalog Data is based on PUSGEN Catalog. It has been public domain data

Competing interests

The authors declare that they have no competing interests

\section{Funding}

In part supported by the Research and Community Services (LPPM), Institute of Technology, Bandung (ITB), Indonesia.

Authors' contributions

Wahyu Triyoso 1*, MSc, Ph.D., BSc, Tedi Yudistira1*, DR, David P. Sahara1*, DR. Rer. Nat

* These authors contributed equally to this work

${ }^{1}$ Global Geophysics Group, Faculty of Mining and Petroleum Engineering, Bandung Institute of Technology, Jl. Ganesha10, Bandung 40132, West Java.

\section{Acknowledgments}

The authors wish to thank Global Geophysics Group, Faculty of Mining and Petroleum Engineering, Bandung Institute of Technology, for supporting to publish this paper. Authors wish thank to Dr. Danny Hilman Natawidjaja for sharing the Active Fault Data of Sumatra 
Island.

\section{Authors' information (optional)}

\section{REFERENCES}

1. Atkinson GM, Boore DM (2006) Earthquake ground-motion prediction equations for Eastern North America. Bull Seismol Soc Am 96(6):2181-2205.

2. Bender, B. (1983). Maximum likelihood estimation of $b$ values for magnitude grouped data, Bull. Seism. Soc. Am., 73, 831-851.

3. Bilham, R.G., Engdahl, E.R., Feldl, N., and Satyabala, S.P. (2005) Partial and complete rupture of the Indo Andaman plate boundary 1847-2004. Seismol. Res. Lett., 76:299-311.

4. Frankel, A. (1995). Mapping seismic hazard in the Central and Eastern United States, Seism. Res. Lett., 66, 4, 8-21.

5. Fukushima Y, Tanaka H (1992) The revision of "A new attenuation relation for peak horizontal acceleration of strong earthquake ground motion in Japan", Abstracts The Seismological Society of Japan, 1992, Fall Meeting, B18 (in Japanese)

6. Gutenberg, B. and C. F. Richter, (1944). Frequency of earthquake in California, Bull. Seism. Soc. Am., 34, 185-188.

7. Katsumata, K., and Kasahara, M. (1999). Precursory seismic quiescence before the 1994 Kurile earthquake $(\mathrm{Mw}=8.3)$ revealed by three independent seismic catalogs. Pure Applied Geophysics, 155(2-4), 443-470.

8. Katsumata, K (2015). A Long - Term Seismic Quiescence before the 2004 Sumatra (Mw 9.1) Earthquake, Bulletin of the Seismological Society of America (2015) 105 (1): 167 - 176.

9. Michael, A.J. (1997). Testing prediction methods: earthquake clustering versus the Poisson model, Geophys. Res. Lett., 24, 1891-1894.

10. Natawidjaja and Triyoso, (2007). The Sumatran Fault Zone - From Source to Hazard, Journal of Earthquake and Tsunami 01(01) DOI: 10.1142/S1793431107000031.

11. Natawidjaja, D. H, (2018), Updating active fault maps and sliprates along the Sumatran Fault Zone, Indonesia. IOP. Conf. Ser. Earth Environ. Sci. 118-012001.

12. Sukrungsri and Pailoplee, (2016). Seismicity Change Prior to Major Earthquakes of the 
Sumatra-Andaman Subduction Zone; Implication for Tectonic Regime, Bulletin of Earth Sciences of Thailand, Vol. 7, No. 1, 16-24.

13. Tim Pusat Studi Gempa Nasional-2017 (The 2017 PuSGen) (2017) Peta Sumber dan Bahaya Gempa Indonesia Tahun 2017. Jakarta: Kementrian Pekerjaan Umum dan Perumahan Rakyat (In Indonesian).

14. Triyoso, W., and Shimazaki, K., (2012). Testing Various Seismic Potential Models for Hazard Estimation Against a Historical Earthquake Catalog in Japan, Earth Planets Space, 64, $673-681$.

15. Triyoso W, Suwondo A, Yudistira T, and Sahara DP. (2020) Seismic Hazard Function (SHF) study of coastal sources of Sumatra Island: SHF evaluation of Padang and Bengkulu cities, Geosci. Lett. (2020) 7:2.

16. Triyoso W, Suwondo A, and Naibaho Z.Y.X. (2020). Analysis The Earthquake Potential Hazard of Palembang City-Sumatra Island (Submitted to and under review in Indonesian Journal Of Geoscience).

17. Tsapanos, T. M., Bayrak, Y., Cinar, H., Koravos, G.C h., Bayrak, E., Kalogirou, E. E., Tsapanou, A. V., and Vougiouka, G. E. (2014). Analysis of largest earthquakes in Turkey and its vicinity by application of the Gumbel III distribution. Acta Geophysica, 62(1) 59-82.

18. Tsapanos, T. M., Yadav, R. B. S., Olasoglou, S. M., and Singh, M. (2016). Assessment of the relative largest earthquake hazard level in the NW Himalaya and its adjacent region. Acta Geophysica, 64(2), 362-378.

19. Wiemer, S., (2001). A software package to analyze seismicity: ZMAP. Seismological Research Letters, 72(2):373-382.

20. Wyss, M., and Habermann, R.E., (1988). Precursory seismic quiescence, Pure Appl. Geophysics; 126, 319-332. 


\section{Figure legends}

Fig 1 The result of the annual seismicity rate model of the study area with a radius of 400km with the center being the epicenter of the earthquake of December 26, 2004, with $\mathrm{Mw} \geqslant 5.0$, generated by data before the RTL period. It is the period of the year of 1963 to 1990 (A). Annual seismicity rate model in the RTL period of the year of 1991 to November 2004(B). The spatial b-value is estimated based on the constant radius of $150 \mathrm{~km}$ of shallow earthquake catalog with $\mathrm{Mc} \sim 4.7, \mathrm{H} \leqslant 50 \mathrm{~km}$ of the years 1963 to $2016(\mathrm{C})$.

Fig 2 The map of Seismic Quiescence Index 'SQI' (A). The integrated result between two models of the subduction zone and active fault sources in which data around subduction zone that is based on the results of Triyoso et al. (2020a) and the active fault data is resulted by the integration between the two models of the A-value of the shallow earthquake catalog weighted by the normalized smoothed seismicity obtained from active fault data (B). The annual seismicity rate model obtained based on the integration between two models (Figure B) weighted by the SQI model (C). The results show that the SQI is consistent with the places of the sorted of major earthquakes that occurred from December 2004 to 2016 with the radius around $300 \mathrm{~km}$.

Fig 3 The mean PGA map of the three different GMPEs (Atkinson et al., 2006, Zhao et al., 1997 and

Fukushima \& Tanaka, 1992) of the $10 \%$ of PE level for 50 years, where SQI is included. The active 
fault (Natawidjaja, 2018) is simplified by the segmented fault model and it is plotted on the map. 


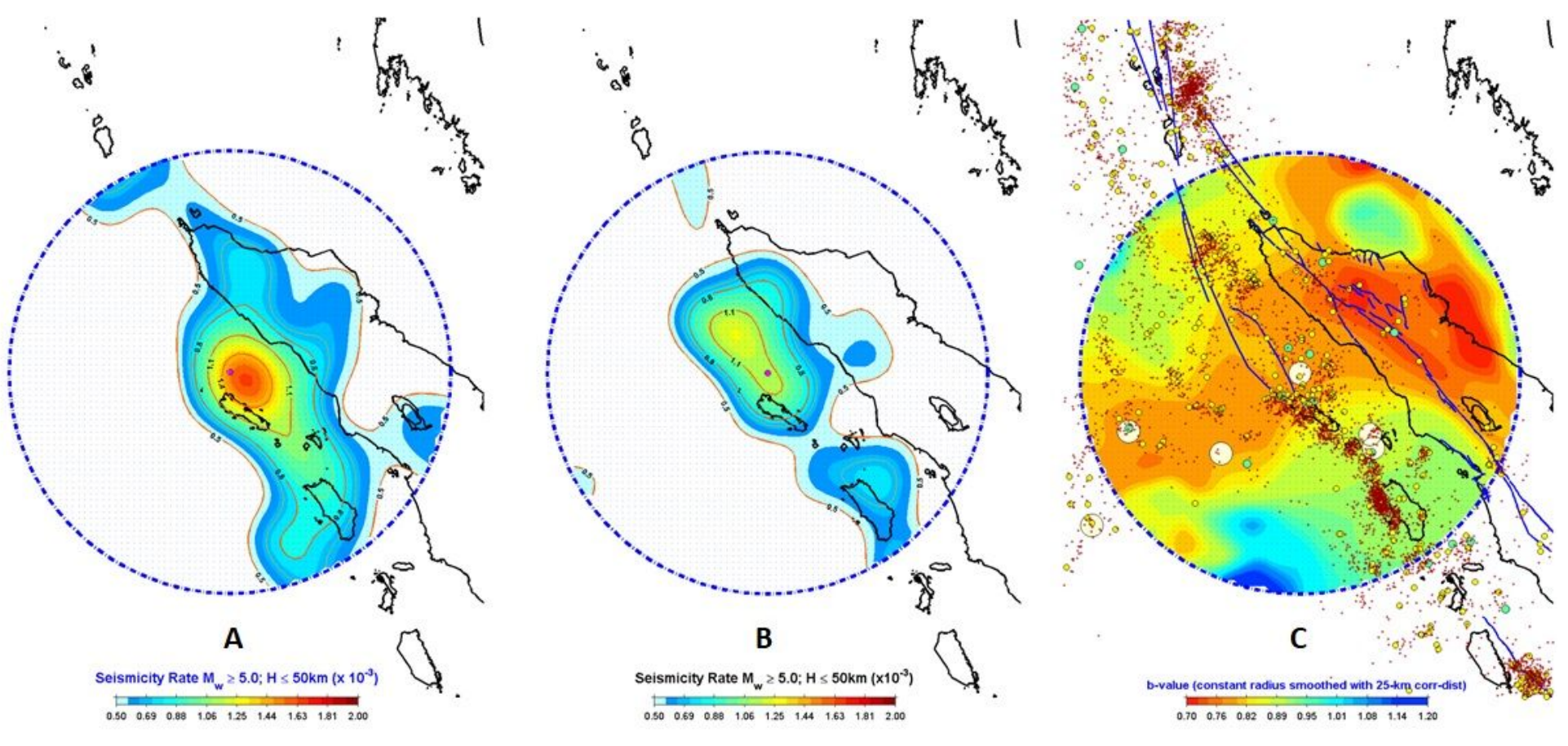

Figure 1

The result of the annual seismicity rate model of the study area with a radius of $400 \mathrm{~km}$ with the center being the epicenter of the earthquake of December 26, 2004, with $M w \geq 5.0$, generated by data before the RTL period. It is the period of the year of 1963 to 1990 (A). Annual seismicity rate model in the RTL period of the year of 1991 to November 2004(B). The spatial b-value is estimated based on the constant radius of $150 \mathrm{~km}$ of shallow earthquake catalog with $\mathrm{Mc} \sim 4.7, \mathrm{H} \leq 50 \mathrm{~km}$ of the years 1963 to 2016 (C).

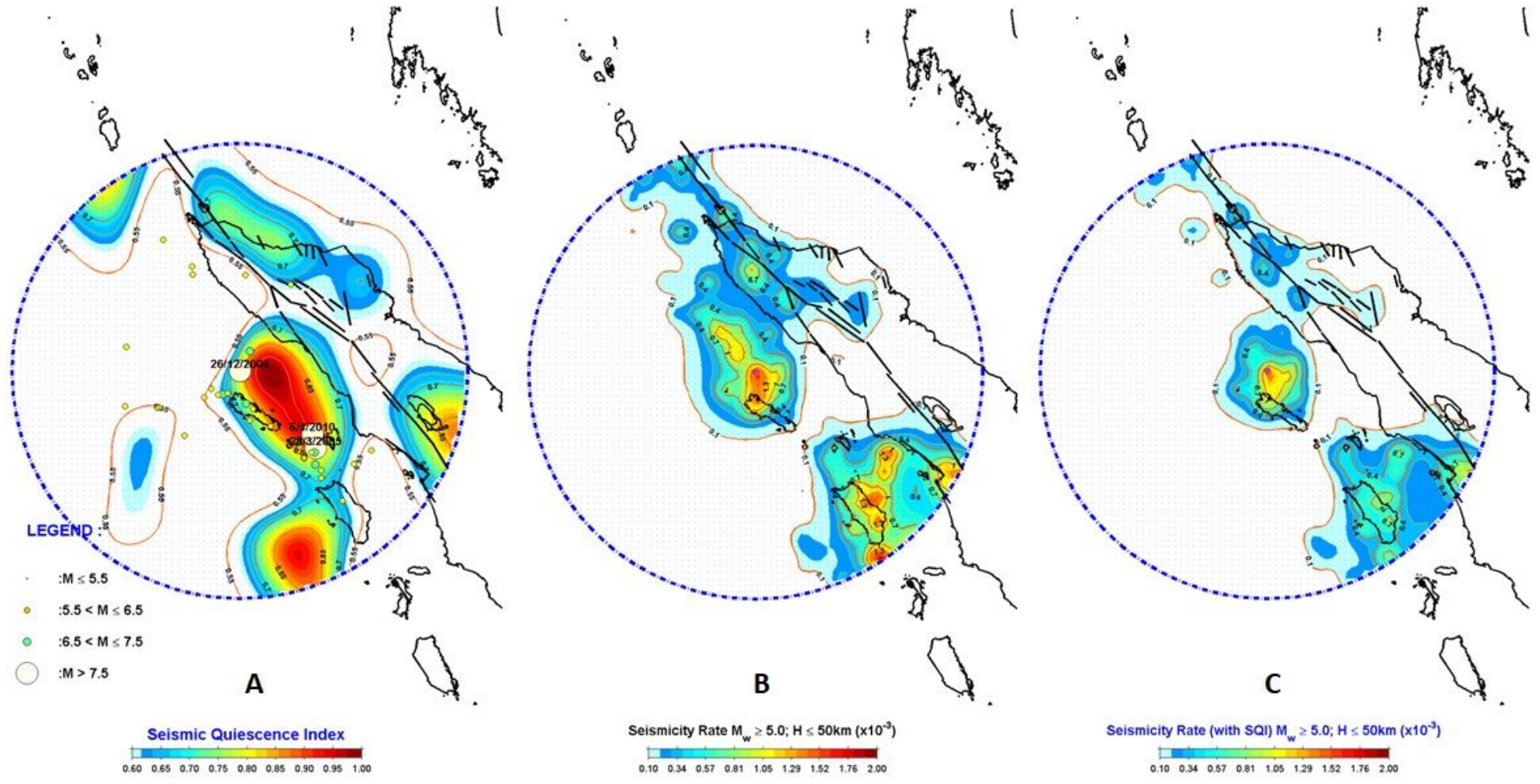


Figure 2

The map of Seismic Quiescence Index 'SQI'(A). The integrated result between two models of the subduction zone and active fault sources in which data around subduction zone that is based on the results of Triyoso et al. (2020a) and the active fault data is resulted by the integration between the two models of the A-value of the shallow earthquake catalog weighted by the normalized smoothed seismicity obtained from active fault data (B). The annual seismicity rate model obtained based on the integration between two models (Figure B) weighted by the SQI model (C). The results show that the SQI isconsistent with the places of the sorted of major earthquakes that occurred from December 2004 to 2016 with the radius around $300 \mathrm{~km}$.

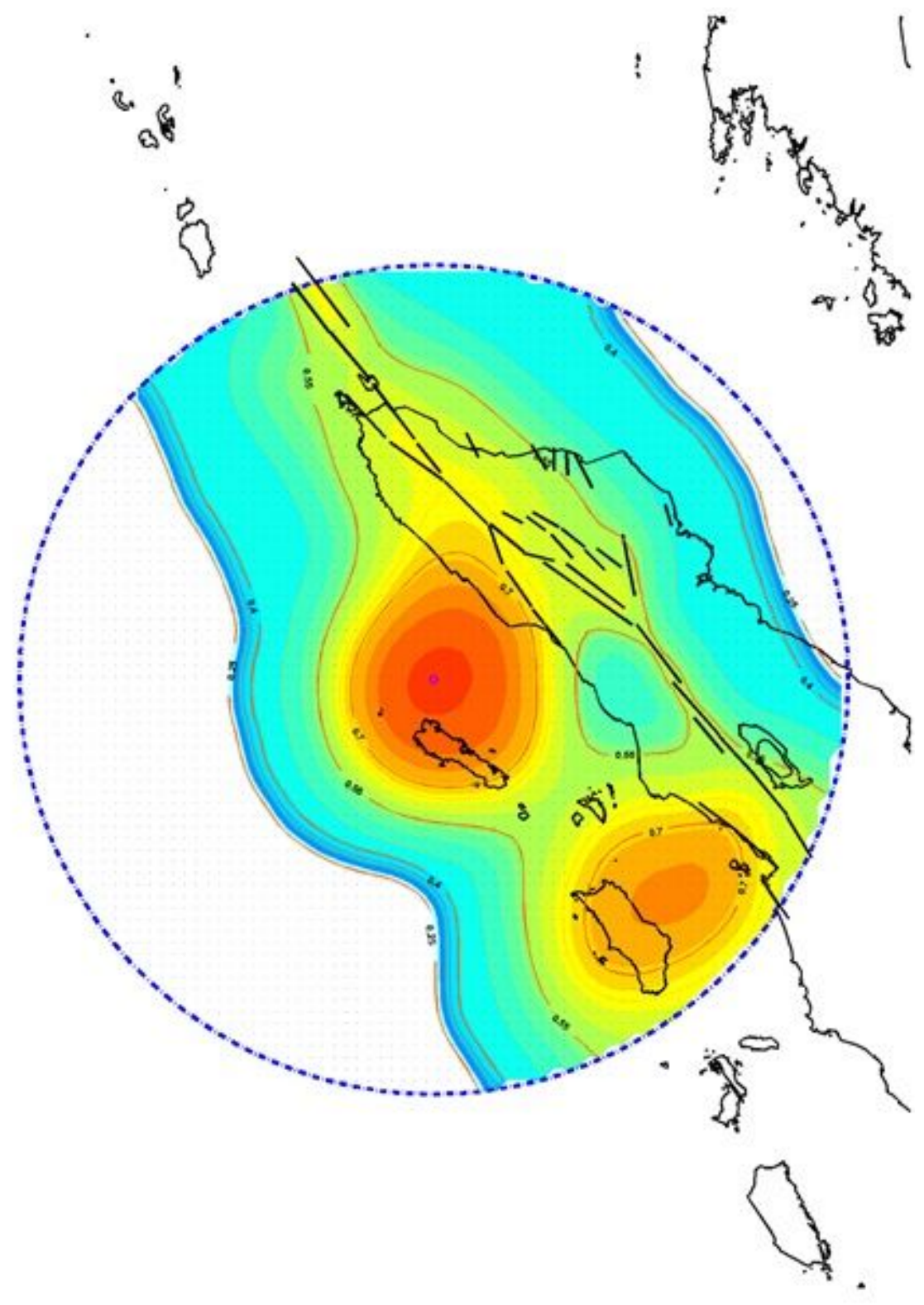

PGA(g) of $10 \%$ Prob.Ex. Level (50years)

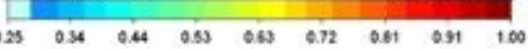

Figure 3 
The mean PGA map of the three differentGMPEs (Atkinson et al., 2006, Zhao et al., 1997 and Fukushima \& Tanaka, 1992) of the $10 \%$ of PE level for 50 years, where SQI is included. The active fault (Natawidjaja, 2018) is simplified by the segmented fault model and it is plotted on the map. 